\title{
Precipitation of jarosite as a purifying procedure of the solution obtained after leaching of zinc secondary material
}

\author{
Andrzej Jarosiński ${ }^{1}$, Artur Przybyła ${ }^{2}$ \\ ${ }^{1}$ Cracow University of Technology, Faculty of Engineering and Chemical Technology, ul. Warszawska 24, 31-155 Kraków, \\ Poland, e-mail: ajar@chemia.pk.edu.pl \\ ${ }^{2}$ BOL-THERM Sp. z o.o., ul. Kolejowa 37, 32-332 Bukowno, Poland
}

\begin{abstract}
Zinc oxide derived from processing of the slime obtained in an industrial process of electrolytic zinc obtaining was leached with the aqueous sulfuric acid solution. The effect of temperature and time on the extent of leaching was determined. The conditions lead to zinc recovery of about $90 \%$. It was found that the extent of arsenic leaching did not depend upon the time and temperature of leaching. Next the conditions of the solution purification procedure were determined. It was found that jarosite formation as well as the degree of arsenic removal is connected with trivalent iron concentration in the solution.
\end{abstract}

Keywords: jarosite, leaching, purification of solution, secondary material.

\section{INTRODUCTION}

In industrial practice zinc secondary materials like zinc scrap or residue obtained in the processes of metallic zinc winning as well as the related processes play more and more role ${ }^{1-3}$. For example, in Great Britain in the process of zinc obtaining about $30 \%$ of raw material is substituted by secondary materials.

Both of the above mentioned materials are processed more frequently in the hydrometallurgical way. Application of the method is connected with the removal of impurities from the solution because the increase of their concentration in the electrolyte is one of the factors liable for the degeneration of cathode zinc quality. Moreover, the presence of impurities in the electrolyte impairs the technical and economic indexes of the process of zinc electrodeposition.

The course of the impurities separation depends on their properties and electrochemical potential. Especially the undesirable impurities in the electrolyte are $\mathrm{Cu}, \mathrm{Cd}$, $\mathrm{As}, \mathrm{Sb}, \mathrm{Fe}$ and the like.

Elimination of both first components from these electrolytes was achieved by cementation using zinc dust. But still the presence of trivalent iron ions in the solution can cause secondary dissolution of copper.

In hydrometallurgy of the non-ferrous metals the problem of iron removal from the solution in the form of the easily filtering deposit is complicated. Typically in the hydrometallurgy of zinc iron is removed as a ferric hydroxide, in particular as hematite, goethite or jarosite ${ }^{4}$.

According to Dutrizac ${ }^{5}$ the jarosite precipitation method owns a lot of advantages, namely high efficiency of iron removal, facility of precipitated jarosite filtration in acidic solutions, minor losses of zinc in the making jarosite coprecipitation, control of sulfates amount in solution and the like. The process can be described by the following equation.

$\mathrm{Me}_{2} \mathrm{SO}_{4}+3 \mathrm{Fe}_{2}\left(\mathrm{SO}_{4}\right)_{3}+6 \mathrm{H}_{2} \mathrm{O} \rightarrow 2 \mathrm{MeFe}_{3}\left(\mathrm{SO}_{4}\right)_{2}(\mathrm{OH})_{6}$ $+6 \mathrm{H}_{2} \mathrm{SO}_{4}$ where: $\mathrm{Me}(\mathrm{I})-\mathrm{Na}^{+}, \mathrm{K}^{+}, \mathrm{NH}_{4}^{+}$
Depending on the salt used $\mathrm{Me}(\mathrm{I})$ adequate form of jarosite is obtained. The thermodynamic analysis at the temperature range of $323-373 \mathrm{~K}$ allows to determine the conditions of potassium or sodium jarosite formation. All considered temperature ranges can create potassium jarosite, however the calculated values of free energy variation indicate that the above $357 \mathrm{~K}$ sodium jarosite can be created. For example, at the temperature of $353 \mathrm{~K}$ the logarithm of equilibrium constant amounts for sodium jarosite -0.06 and potassium jarosite 5.432, for example at $353 \mathrm{~K}$ logarithm of equilibrium constant amounts for sodium jarosite -0.06 , whereas for potassium jarosite achieves the 5.432 value. At $373 \mathrm{~K}$ these constants reach the 2.239 and 5.914 values, respectively. The data indicates that the efficiency of trivalent iron ions in the presence of potassium ions is higher than with sodium ions.

Zinc raw materials contain various impurities, for example iron or arsenic, which have to be removed ahead of zinc electrodeposition.

The aim of this paper was to determine the efficiency of zinc leaching by sulphuric (VI) acid solutions from zinc oxide deriving from processing slime after zinc electrolysis as well as arsenic removal from the solution at the same time when potassium jarosite precipitation takes place.

\section{EXPERIMENTAL}

The topic of the research was zinc oxide derived from the processing of slime obtained in the industrial process of electrolytic zinc winning. The representative initial material was dried at $105^{\circ} \mathrm{C}$ for 24 hours and then its chemical and phase composition was determined. Its chemical composition entered into Table 1.

The X-ray investigations were carried out with the use of the Philips diffractometer system XPERT. X-ray examination showed that the initial material contained $\mathrm{ZnO}$ as a major phase, as well as anglesite - $\mathrm{PbSO}_{4}$ and magnetite- $\mathrm{Fe}_{3} \mathrm{O}_{4}$ as the minor phases.

Table 1. The chemical composition of zinc oxide obtained from processing of slime derived from the electrodeposition process

\begin{tabular}{|l|c|c|c|c|c|c|c|}
\hline Component & $\mathrm{Zn}$ & $\mathrm{Pb}$ & $\mathrm{Fe}$ & $\mathrm{As}$ & $\mathrm{Cd}$ & $\mathrm{Cl}$ & $\mathrm{F}$ \\
\hline Content [wt.\%] & 44.90 & 17.30 & 5.58 & 0.30 & 1.06 & 0.99 & 0.03 \\
\hline
\end{tabular}


The tests were carried out in a glass reactor. The mixture was stirred with a constant speed by a mechanical stirrer (80 r.p.m.) fitted with a stainless steel impeller. A sample of zinc oxide in the amount of 100 gram and $8 \%$ solution of sulfuric acid were used for leaching. In all the tests the weight ratio of solid to liquid phase equal to $1 / 9$. Experiments were performed at temperatures ranging from 60 to $90^{\circ} \mathrm{C}$ for 1 to 3 hours.

Next, the leachates and solids were analyzed by filtration under vacuum in the Buchner-type filter to estimate the contents of some components.

The extent of leaching for the chosen components was calculated from the following dependence:

$$
\alpha=\frac{V_{R} \cdot c_{i}}{m_{p} \cdot \frac{x_{i}}{100}} \cdot 100[\%]
$$

where: / the extent of leaching, of "i" component [\%],V volume of the solution after leaching $\left[\mathrm{dm}^{3}\right]$, m-mass of the used sample for leaching [g], $\mathrm{x}$ - content of " $\mathrm{i}$ " component in the sample after leaching [wt pct].

As the next step after the leaching the solutions were purified. This procedure included: enrichment of the solution in ions $\mathrm{Fe}(\mathrm{II})$ by adding- $\mathrm{FeSO}_{4} \cdot 7 \mathrm{H}_{2} \mathrm{O}$ in the required quantity, oxidation $\mathrm{Fe}(\mathrm{II})$ to $\mathrm{Fe}(\mathrm{III})$ by means of $\mathrm{KMnO}_{4}$ and precipitation of potassium jarosite.

The obtained results of the chemical analyses of the solution before and after the process of jarosite precipitation were taken as a basis for the degree of some components removal. The values of this degree were determined from the relationship:

$\beta=\frac{V_{P} \cdot c_{p_{i}}-V_{k} \cdot c_{k_{i}}}{V_{p} \cdot c_{p_{i}}} \cdot 100[\%]$

where: $V_{p}-$ volume of the initial solution, $V_{k}-$ volume of the final solution $c_{p i}-$ concentration of " $i$ " component in the initial solution, $c_{\mathrm{ki}}$ - concentration of " $\mathrm{i}$ " component in the final solution.

\section{RESULTS AND DISCUSSION}

The research was carried out in order to find the way of purifying with the solutions derived from leaching of zinc oxide with sulfuric acid. The first stage of testing consisted in the determination of temperature and leaching time effect on the extent of leaching. The obtained results are shown in Table 2. As it can be seen from this data, time and process temperature have an essential ef-
Table 2. The extent of leaching of some components from zinc oxide

\begin{tabular}{|c|c|c|c|c|}
\hline \multicolumn{2}{|c|}{ Conditions of process } & \multicolumn{3}{|c|}{ Extent of leaching [\%] } \\
\hline $\mathrm{t}[\mathrm{h}]$ & $\mathrm{T}\left[{ }^{\circ} \mathrm{C}\right]$ & $\mathrm{Zn}$ & $\mathrm{As}$ & $\mathrm{Fe}$ \\
\hline \multirow{4}{*}{1} & 60 & 82.18 & 70.47 & 12.01 \\
\cline { 2 - 5 } & 70 & 83.07 & 78.83 & 13.80 \\
\cline { 2 - 5 } & 80 & 83.96 & 73.83 & 15.77 \\
\cline { 2 - 5 } & 90 & 86.64 & 77.18 & 17.20 \\
\hline \multirow{4}{*}{2} & 60 & 83.07 & 73.83 & 13.98 \\
\cline { 2 - 5 } & 70 & 84.41 & 73.83 & 15.95 \\
\cline { 2 - 5 } & 80 & 85.30 & 77.18 & 16.49 \\
\hline \multirow{4}{*}{3} & 90 & 86.64 & 77.18 & 18.28 \\
\cline { 2 - 5 } & 60 & 87.31 & 73.83 & 14.70 \\
\cline { 2 - 5 } & 70 & 87.53 & 73.83 & 16.31 \\
\cline { 2 - 5 } & 80 & 87.75 & 77.18 & 17.38 \\
\hline
\end{tabular}

fect on the extent of zinc leaching. The chemical composition of the obtained solutions after leaching is given in Table 3.

The degrees of some components extraction are specified in Table 4 and plotted on the graphs in Fig.1. The phase composition of solid products obtained by precipitation of jarosite is given in Fig. 2. The results of X-ray diffraction analysis indicate that in the whole tested solid product potassium jarosite was only present. The above data indicates that in the course of potassium jarosite precipitation losses of zinc were small. The increase of trivalent iron concentration in the solution a little rise of zinc extraction was observed. The highest zinc content amounted to $11.3 \%$, which corresponds to $7 \mathrm{~g} / \mathrm{dm}$ trivalent iron concentration. The shapes of the curves in Fig.1 allowed us to state that the elimination of sodium ions from the tested solutions proceeds similarly to the removal of zinc. On this assumption it may be supposed that in these conditions sodium jarosite was not formed. A high degree of potassium removal the from tested solutions with the increase of the mass of the formed potassium compound was observed, which confirms the formation of this jarosite in the course of the purification process. The degree of trivalent iron ions removal from the solution achieved even $95.43 \%$.

In the course of the purification of the solutions arsenic was removed. The highest degree of the removal of this element was achieved for trivalent iron concentration equal to $4 \mathrm{~g} / \mathrm{dm}^{3}$ and amounted to $82.38 \%$. Higher iron concentration brought about a slight decrease of the degree of

Table 3. Concentrations of some components in the solution after leaching

\begin{tabular}{|c|c|c|c|c|c|c|}
\hline \multicolumn{2}{|c|}{ Conditions of process } & \multicolumn{4}{|c|}{ Concentration $\left[\mathrm{g} / \mathrm{dm}^{3}\right]$} & \multirow{2}{*}{$\mathrm{pH}$} \\
\hline $\mathrm{t}[\mathrm{h}]$ & $\mathrm{T}\left[{ }^{\circ} \mathrm{C}\right]$ & $\mathrm{Zn}$ & $\mathrm{Na}$ & As & $\mathrm{Fe}$ & \\
\hline \multirow{4}{*}{1} & 60 & 36.9 & 0.24 & 0.21 & 0.67 & 1.33 \\
\hline & 70 & 37.3 & 0.25 & 0.22 & 0.77 & 1.41 \\
\hline & 80 & 37.7 & 0.25 & 0.22 & 0.88 & 1.42 \\
\hline & 90 & 38.9 & 0.26 & 0.23 & 0.96 & 1.45 \\
\hline \multirow{4}{*}{2} & 60 & 37.3 & 0.26 & 0.22 & 0.78 & 1.36 \\
\hline & 70 & 37.9 & 0.26 & 0.22 & 0.89 & 1.43 \\
\hline & 80 & 38.3 & 0.27 & 0.23 & 0.92 & 1.45 \\
\hline & 90 & 38.9 & 0.27 & 0.23 & 1.02 & 1.47 \\
\hline \multirow{4}{*}{3} & 60 & 39.2 & 0.27 & 0.22 & 0.82 & 1.39 \\
\hline & 70 & 39.3 & 0.27 & 0.22 & 0.91 & 1.45 \\
\hline & 80 & 39.4 & 0.27 & 0.23 & 0.97 & 1.46 \\
\hline & 90 & 39.5 & 0.28 & 0.23 & 1.06 & 1.50 \\
\hline
\end{tabular}


Table 4. The solution composition after jarosite precipitation

\begin{tabular}{|c|c|c|c|c|c|c|}
\hline \multirow{2}{*}{ Concentration of $\mathrm{Fe}(\mathrm{III})$ in solution $\left[\mathrm{g} / \mathrm{dm}^{3}\right]$} & \multicolumn{5}{|c|}{ Concentration of some components in solution $\left[\mathrm{g} / \mathrm{dm}^{3}\right]$} & \multirow{2}{*}{$\mathrm{pH}$} \\
\hline & $\mathrm{Zn}$ & $\mathrm{Fe}$ & As & $\mathrm{K}$ & $\mathrm{Na}$ & \\
\hline 0.86 & 39.6 & 0.73 & 0.186 & 0.70 & 0.25 & 1.44 \\
\hline 2 & 39.3 & 0.68 & 0.121 & 0.61 & 0.25 & 1.43 \\
\hline 3 & 38.5 & 0.64 & 0.082 & 0.53 & 0.24 & 1.40 \\
\hline 4 & 38.2 & 0.72 & 0.037 & 0.43 & 0.24 & 1.38 \\
\hline 5 & 38.1 & 0.61 & 0.040 & 0.42 & 0.23 & 1.36 \\
\hline 6 & 36.1 & 0.72 & 0.046 & 0.39 & 0.23 & 1.34 \\
\hline 7 & 36.0 & 0.66 & 0.046 & 0.32 & 0.23 & 1.30 \\
\hline
\end{tabular}

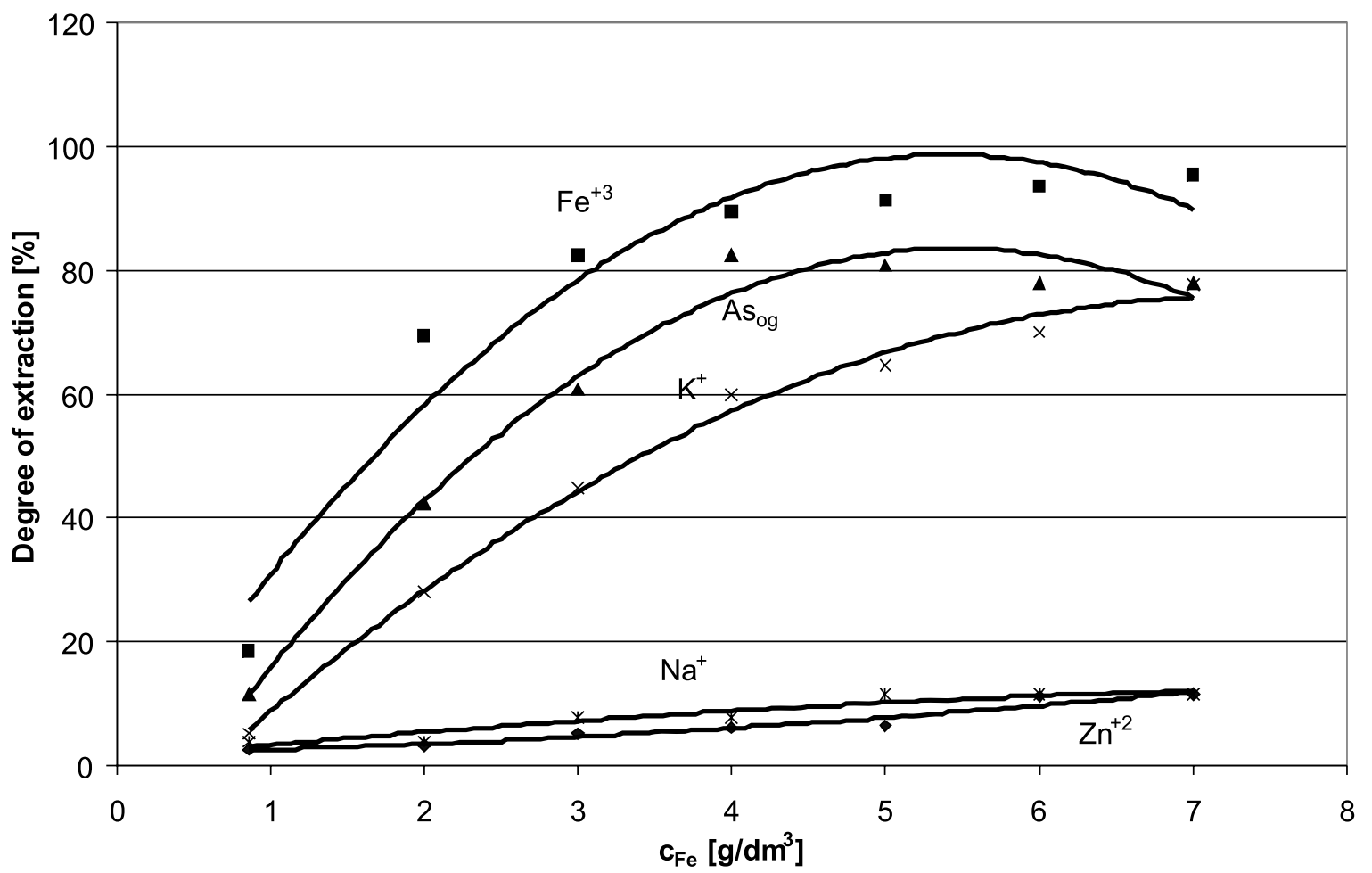

Figure 1. Relationship between the degree of the chosen component extraction and iron concentration

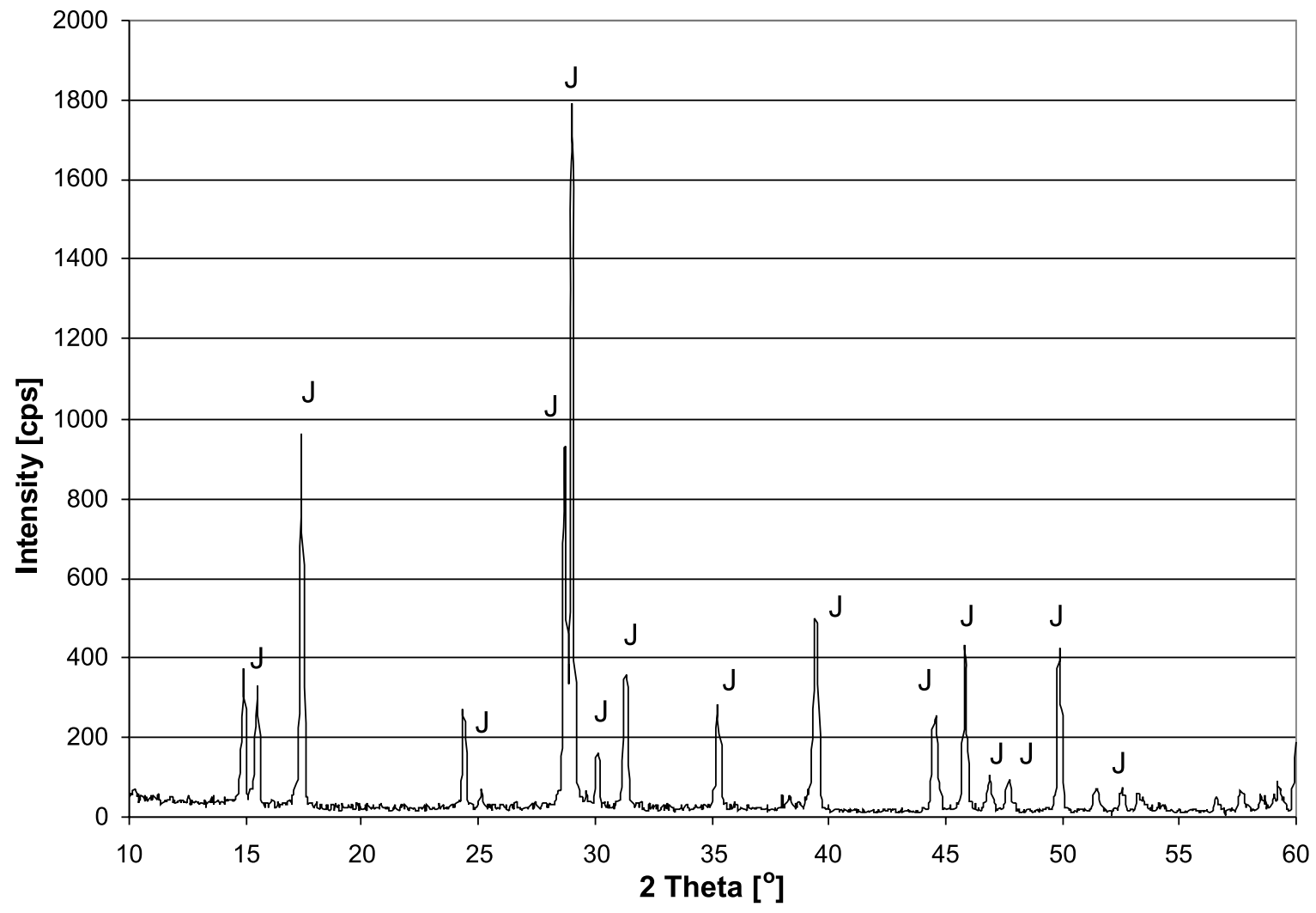

J - Jarosite $\left(\mathrm{KFe}_{3}(\mathrm{SO})_{4}(\mathrm{OH})_{6}\right)$

Figure 2. X-ray diffraction pattern of product obtained in course of purification solution 
Table 5. The chemical composition of the solid product obtained in the course jarosite precipitation

\begin{tabular}{|c|c|c|c|c|c|}
\hline \multirow{2}{*}{$\begin{array}{c}\text { Concentration of } \\
\mathrm{Fe}(\mathrm{III}) \text { in solution } \\
{\left[\mathrm{g} / \mathrm{dm}^{3}\right]}\end{array}$} & \multicolumn{5}{|c|}{ Content [wt. \%] } \\
\hline & $\mathrm{Zn}$ & $\mathrm{Fe}$ & As & K & $\mathrm{Na}$ \\
\hline 0.86 & 2.65 & 23.8 & - & 0.10 & 5.32 \\
\hline 2 & 1.61 & 29.1 & 2.42 & 0.05 & 6.39 \\
\hline 3 & 1.40 & 30.3 & 1.41 & 0.06 & 6.33 \\
\hline 4 & 1.39 & 33.2 & 1.48 & 0.06 & 6.20 \\
\hline 5 & 1.41 & 31.6 & 1.14 & 0.05 & 5.85 \\
\hline 6 & 1.26 & 30.5 & 0.96 & 0.04 & 5.85 \\
\hline 7 & 1.32 & 30.8 & 0.75 & 0.06 & 5.78 \\
\hline
\end{tabular}

arsenic extraction. Considering that the increase of jarosite mass causes a decrease of the $\mathrm{pH}$ of the solution and creates a by-product -sulfuric (VI) acid, according to the reaction:

$3 \mathrm{Fe}_{2}\left(\mathrm{SO}_{4}\right)_{3}+\mathrm{Me}_{2} \mathrm{SO}_{4}+12 \mathrm{H}_{2} \mathrm{O}=2 \mathrm{MeFe}\left(\mathrm{SO}_{4}\right)_{2}(\mathrm{OH})_{6}$ $+6 \mathrm{H}_{2} \mathrm{SO}_{4}$

which can cause the decrease of arsenic removal from the solution.

Taking into account a high degree of iron and arsenic removal from the tested solutions as well as little losses of zinc it can be confirmed that this purification method is characterized by high efficiency.

\section{CONCLUSION}

Based on the results of the research described herein, the following conclusions can be made:

- The extent of zinc leaching depends in a distinct manner on the temperature and time reaching the maximum value about $90 \%$ at $90^{\circ} \mathrm{C}$ after 3 hours.

- Likewise the high extent of arsenic leaching received, but this value does not depend upon the time of leaching and the process temperature.

- The efficiency of iron leaching is relatively low but it increases with the rise of time and process temperature.

- It was found that jarosite formation as well as the degree of arsenic removal is connected with trivalent iron concentration in the solution.

- The method of iron and arsenic removal from the solution is selective in relation to zinc and at $\mathrm{pH} 1.4$ in the presence trivalent iron ions the process runs with high efficiency.

- It should be pointed out that the purification method of the tested solution is uncomplicated and the obtained deposit is well filterable.

\section{LITERATURE CITED}

1. Jha, M.K., Kumar, V. \& Singh, R.J., (2001). Review of hydrometallurgical recovery of zinc from industrial wastes, Resources Conservation, Recycling, 33, $1-22$.

2. Jarosiński, A, (2007). Exemplary solutions of zinc raw material processing, Waste recycling XI, Kosice, 6-7 December, $177-184$.

3. Malinowski, Cz., Małecki, S. \& Jochymek, Ł. (2007), Alternative way of zinc secondary material processing, IX International Conference "Theoretical and practical problems of management of metallurgical and industrial wastes", 16-18 May, 89-95, AGH Faculty of Non-ferrous, 89 - 95 (in Polish).
4. Łętowski, F, (1975). Basic of hydrometallurgy. WNT Warszawa (in Polish).

5. Dutrizac, J.E, (1984). The behavior of impurities during jarosite precipitation, Ed. Bautista R.G. "Hydrometallurgical process fundamentals" Part I, Plenum Press, New York and London, 125 - 169. 